\title{
Growth, spectroscopy and diode-pumped laser operation of acentric Yb:KGd($\left(\mathrm{PO}_{3}\right)_{4}$ crystal
}

\author{
Shanming Li ${ }^{1,2}$, Anna Volokitina ${ }^{1,3, *}$, Rosa Maria Solé1, Pavel Loiko ${ }^{4}$, Valentin Petrov ${ }^{5}$, Uwe Griebner ${ }^{5}$, \\ Yin Hang ${ }^{2}$, Francesc Díaz ${ }^{1}$, Magdalena Aguiló ${ }^{1}$ and Xavier Mateos ${ }^{1}$ \\ 1. Universitat Rovira i Virgili (URV), FiCMA-FiCNA-EMaS, Marcel.li Domingo 1, 43007 Tarragona, Spain \\ 2. Laboratory of Micro-Nano Photonic and Optoelectronic Materials and Devices, Key Laboratory of Materials for High Power Laser, \\ Shanghai Institute of Optics and Fine Mechanics, Chinese Academy of Sciences, 201800 Shanghai, China \\ 3. ITMO University, 49 Kronverkskiy Pr., 197101 St. Petersburg, Russia.*E-mail: anna.itmo@gmail.com \\ 4. CIMAP, UMR 6252 CEA-CNRS-ENSICAEN, Université de Caen Normandie, 6 Boulevard du Maréchal Juin, 14050 Caen, France \\ 5. Max-Born-Institute for Nonlinear Optics and Short-Pulse Spectroscopy, 2A Max-Born-Str., 12489 Berlin, Germany
}

Bifunctional crystals capable of hosting laser-active rare-earth ions and allowing for frequency doubling are of interest for applications in compact visible lasers. This can be realized in crystals exhibiting non-centrosymmetric structure, which provides the necessary $\chi^{(2)}$ nonlinearity. So far, such crystals were mainly doped with $\mathrm{Nd}^{3+}$ ions. However, ytterbium $\left(\mathrm{Yb}^{3+}\right)$ ions are also very attractive for such laser designs as they provide longer upper laser level lifetimes, higher Stokes pump efficiency, weaker heat loading and broader emission bandwidths which is of interest for the generation of fs pulses in the green spectral range [1]. In the present work, we report on the growth, polarized spectroscopy and first diode-pumped laser operation of an acentric crystal, $\mathrm{Yb}: \mathrm{KGd}_{(}\left(\mathrm{PO}_{3}\right)_{4}$.

The $\mathrm{Yb}: \mathrm{KGd}\left(\mathrm{PO}_{3}\right)_{4}$ crystals were grown by the top-seeded solution growth slow-cooling method, Fig. 1(a). The doping concentration was measured by electron probe microanalysis, $N_{\mathrm{Yb}}=1.0 \times 10^{20} \mathrm{~cm}^{-3}(2.4 \mathrm{at} \% \mathrm{Yb})$. $\mathrm{Yb}: \mathrm{KGd}\left(\mathrm{PO}_{3}\right)_{4}$ is monoclinic (sp. gr. $P 2_{1}$ ) and optically biaxial (it is phase-matchable for type I second harmonic generation) [2]. The absorption, $\sigma_{\mathrm{abs}}$, and stimulated-emission (SE), $\sigma_{\mathrm{SE}}$, cross-sections for $\mathrm{Yb}^{3+}$ measured for light polarized along the optical indicatrix axes are shown in Fig. 1(b). The maximum $\sigma_{\mathrm{SE}}$ in the region where the laser operation is expected, amounts to $0.73 \times 10^{-20} \mathrm{~cm}^{2}$ at $1006 \mathrm{~nm}$ for $\boldsymbol{E} \| N_{\mathrm{m}}$. The radiative lifetime of the ${ }^{2} \mathrm{~F}_{5 / 2}$ multiplet is relatively long, $1.22 \mathrm{~ms}$. The Stark splitting for $\mathrm{Yb}^{3+}$ resolved at $6 \mathrm{~K}$ is shown in Fig. 1(c).
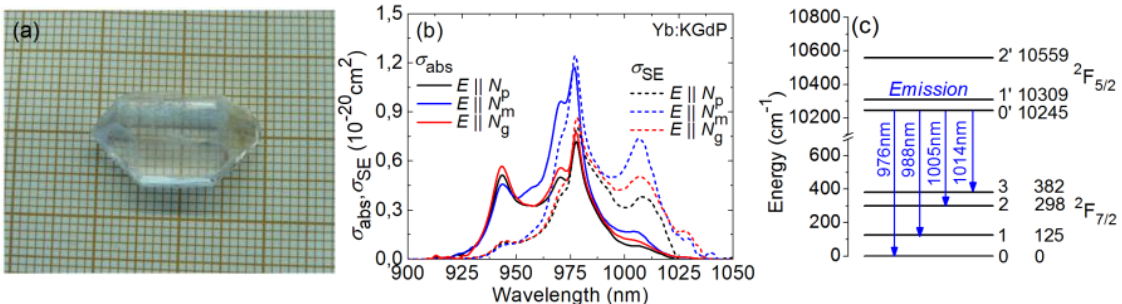

Fig. 1 Growth and spectroscopy of $\mathrm{Yb}: \mathrm{KGd}_{(}\left(\mathrm{PO}_{3}\right)_{4}$ : (a) Photograph of the as-grown crystal; (b) absorption, $\sigma_{\text {abs }}$, and stimulatedemission, $\sigma_{\mathrm{SE}}$, cross-sections for $\mathrm{Yb}^{3+}$ ions with polarized light; (c) crystal-field splitting of $\mathrm{Yb}^{3+}$ multiplets.

Laser operation of $\mathrm{Yb}: \mathrm{KGd}\left(\mathrm{PO}_{3}\right)_{4}$ at the fundamental wavelength $(\sim 1 \mu \mathrm{m})$ was achieved under diode-pumping by a fiber-coupled InGaAs laser diode at $966 \mathrm{~nm}$. The $N_{\mathrm{g}}$-cut uncoated crystal was $7.03 \mathrm{~mm}$-thick; it was mounted in a $\mathrm{Cu}$-holder cooled by flowing water $\left(14^{\circ} \mathrm{C}\right)$. A compact plano-plano cavity was employed and the laser mode was stabilized by the positive thermal lens in the crystal. The laser generated a maximum output power of $1.57 \mathrm{~W}$ at $1040.7 \mathrm{~nm}$ with a slope efficiency of $44.4 \%$ (vs. absorbed pump power) and a threshold of $0.68 \mathrm{~W}$ (for transmission of the output coupler $\left.T_{\mathrm{OC}}=0.5 \%\right)$, Fig. 2(a). The laser emission was linearly polarized $\left(\boldsymbol{E} \| N_{\mathrm{m}}\right)$ and the wavelength experienced a blue-shift with $T_{\mathrm{OC}}$, Fig. 2(b). The laser operated at the fundamental mode, Fig. 2(c).

$\mathrm{Yb}: \mathrm{KGd}\left(\mathrm{PO}_{3}\right)_{4}$ is promising for mode-locked lasers with self-frequency-doubling yielding green fs pulses.
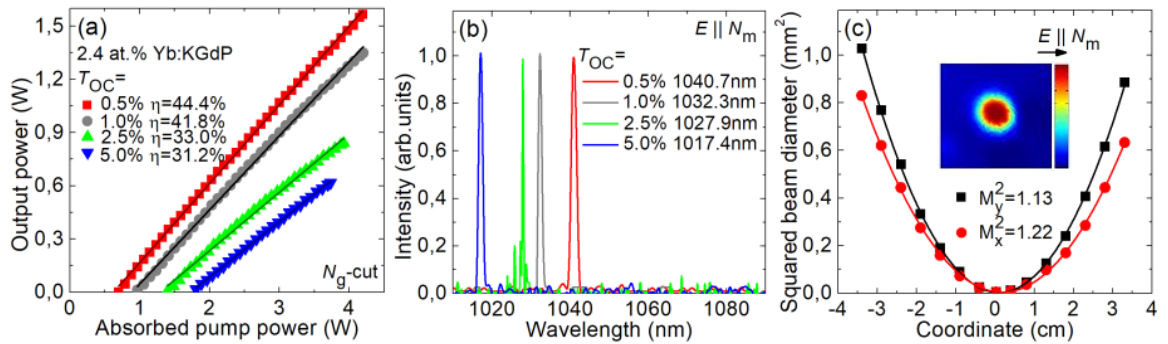

Fig. 2 Diode-pumped 2.4 at.\% $\mathrm{Yb}^{3+}: \mathrm{KGd}_{(}\left(\mathrm{PO}_{3}\right)_{4}(\mathrm{Yb}: \mathrm{KGdP})$ laser: (a) Input-output dependences, $\eta$ - slope efficiency; (b) typical spectra; (c) evaluation of the beam quality factors, $\mathrm{M}_{\mathrm{x}, \mathrm{y}}^{2}$; inset: far-field mode profile, $T_{\mathrm{OC}}=0.5 \%, P_{\mathrm{abs}}=3.6 \mathrm{~W}$. The laser polarization is $\boldsymbol{E} \| N_{\mathrm{m}}$ (horizontal, $\| x$ ).

\section{References}

[1] M. Kowalczyk, X. Zhang, X. Mateos, S. Guo, Z. Wang, X. Xu, P. Loiko, J. E. Bae, F. Rotermund, J. Sotor, U. Griebner, and V. Petrov, "Graphene and SESAM mode-locked Yb:CNGS lasers with self-frequency doubling properties," Opt. Express 27(2), 590-596 (2019).

[2] I. Parreu, M. C. Pujol, M. Aguiló, F. Díaz, X. Mateos, and V. Petrov, "Growth, spectroscopy and laser operation of Yb:KGd($\left(\mathrm{PO}_{3}\right)_{4}$ single crystals," Opt. Express 15(5), 2360-2368 (2007). 